Note

\section{Isolation of Soyasaponin I as an Inhibitor for Glycolate Oxidase}

\author{
Makoto Nishida, Suong-Be Hyeon, \\ Akira IsOGAI \\ and Akinori SuZuKI
}

Department of Agricultural Chemistry, The University of Tokyo, Bunkyo-ku, Tokyo 113, Japan

Received May 7, 1981

The photorespiration proceeds on the glycolate pathway to reduce the apparent photosynthesis of $C_{3}$ plants and glycolated oxidase (EC 1.1.3.1) is involved in the process. Untill now, several chemicals such as $\alpha$-hydroxypyridinemethanesulfonate ( $\alpha$-HPMS), ${ }^{1)}$ butyl hydroxybutynoate (BHB), ${ }^{2)}$ and glyoxylate ${ }^{3)}$ have been known to inhibit glycolate oxidase, and it is of interest to study on their effects on the glycolate pathway. Further it has been reported that, under suitable conditions, these inhibitors block the photorespiration and increase the photosynthetic $\mathrm{CO}_{2}$ uptake. ${ }^{4)}$

With a view to find potent inhibitors of the photorespiration, we have continued to search for the inhibitors of glycolate oxidase and have prevoiusly reported that some fatty acids inhibit the enzyme. ${ }^{5)}$ During the study, an extract of soybean meal showed an inhibitory activity on glycolate oxidase, and in this paper we wish to report isolation of soyasaponin I (1) from the soybean meal as an inhibitor of glycolate oxidase.

The partially purified glycolate oxidase was prepared from spinach leaves, Spinacia oleracea, according to the method reported by Zelitch ${ }^{6)}$ and the bioassay method used in the present experiments was the same as that in the previous report. ${ }^{5)}$

Five hundred grams of soybean meal was dipped in approximately 5 liters of water-methanol mixture $(1: 1)$ for a day and, after filtration, the filtrate was concentrated in vacuo to 2 liters. The residue was extracted with ethyl acetate at pH 2.0 and the organic layer was extracted with saturated sodium bicarbonate solution. The aqueous layer was acdified to $\mathrm{pH} 2$ and then extracted with ethyl acetate. The extract was concentrated in vacuo to afford a solid $(5.6 \mathrm{~g})$. The solid was dissolved in $10 \mathrm{ml}$ of methanol and the solution was added to $500 \mathrm{ml}$ of ethyl acetate giving a precipitate $(1.3 \mathrm{~g})$. The precipitate was successivey chromatographed on a silica gel $\mathrm{PF}_{254}$ column using chloroform-methanol-acetic acid-water $(12: 6: 1: 1)$ as a solvent system and then on a Sephadex LH-20 column using ethyl acetate-methanol $(8: 2)$ to afford $65 \mathrm{mg}$ of the active principle (1).

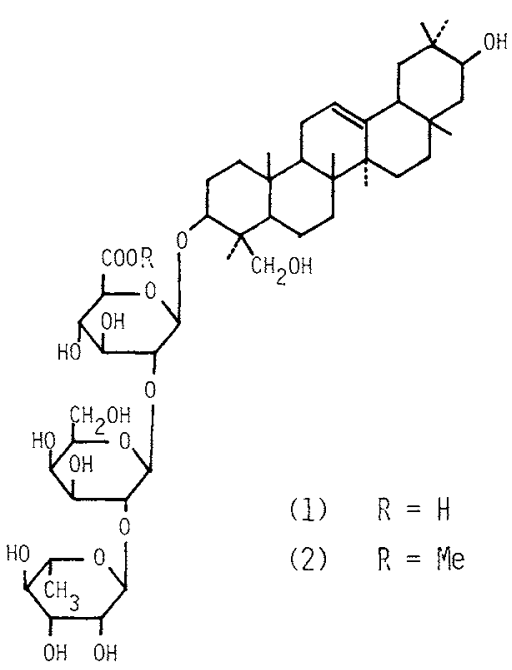

The IR spectrum of $\mathbf{1}$ indicated the presence of a hydroxyl group $\left(v_{\max }^{\text {nujol }} 3400 \mathrm{~cm}^{-1}\right)$ and a carboxyl $(2800$ 2400 and $1730 \mathrm{~cm}^{-1}$ ). By treatment with diazomethane, 1 was converted to its methyl ester (2). The ${ }^{13} \mathrm{C}-\mathrm{NMR}$ of 2 showed the signals due to 49 carbons including an ester carbonyl carbon $\left(\delta_{\mathrm{CD}_{3} \mathrm{OD}}^{\mathrm{TMS}} 172.2\right)$, two double bond carbons $(\delta 123.6$ and 145.2) and three anomeric carbons $(\delta 105.7$, 102.2 and 102.2).

By refluxing with $1 \mathrm{~N}$ hydrochloric acid in dioxan-water $(1: 2)$ mixture for $6 \mathrm{hr}, 1$ was hydrolyzed and the reaction mixture was extracted with ethyl acetate. The aqueous residue was concentrated and treated with TMS-HT reagent to give TMS derivatives of sugars, which were identified as those of rhamnose, galactose and glucuronic acid by GLC. The ethyl acetate extract was chromatographed on a silica gel $\mathrm{PF}_{254}$ column $(1.5 \times 50 \mathrm{~cm})$ using chloroform-ethyl acetate mixture $(8: 2)$ as a solvent system to afford the aglycon (3).

The molecular formula of $\mathbf{3}$ was determined as $\mathrm{C}_{30} \mathrm{H}_{50} \mathrm{O}_{3}$ through mass spectrometry: $\mathrm{MS} m / z, 458\left(\mathrm{M}^{+}\right)$; High MS $m / z, 425.3423\left(\mathrm{M}-\mathrm{H}_{2} \mathrm{O}-\mathrm{CH}_{3}\right.$, calcd. for $\left.\mathrm{C}_{29} \mathrm{H}_{45} \mathrm{O}_{2} \mathrm{~m} / z, 425.3427\right)$. The ${ }^{1} \mathrm{H}-\mathrm{NMR}$ and ${ }^{13} \mathrm{C}-\mathrm{NMR}$ of 3 indicated the presence of 7 methyl groups $\left({ }^{1} \mathrm{H}-\mathrm{NMR}\right.$; $\delta_{\mathrm{TMS}}^{\mathrm{CDCl}_{3}} 0.88(3 \mathrm{H}), 0.90(3 \mathrm{H}), 0.96(3 \mathrm{H}), 1.04(3 \mathrm{H})$ and $1.22(3 \mathrm{H}))$, a double bond $\left({ }^{1} \mathrm{H}-\mathrm{NMR} ; \delta 5.25(1 \mathrm{H}, \mathrm{t}),{ }^{13} \mathrm{C}\right.$ NMR; $\delta_{\mathrm{TMS}}^{\mathrm{CDCl}_{3}} 144.0$ and 122.4$)$, two secondary hydroxyl groups $\left({ }^{1} \mathrm{H}-\mathrm{NMR} ; \delta 3.43(1 \mathrm{H}, \mathrm{t})\right.$ and $3.60(1 \mathrm{H}, \mathrm{dd}),{ }^{13} \mathrm{C}$ NMR; $\delta 81.0$ and 76.7) and one hydroxymethyl group $\left({ }^{1} \mathrm{H}-\mathrm{NMR} ; \delta 3.34(1 \mathrm{H}, \mathrm{d})\right.$ and $4.21(1 \mathrm{H}, \mathrm{d}),{ }^{13} \mathrm{C}-\mathrm{NMR} ; \delta$ 64.6). Based on these data, 3 was inferred to be soyasapogenol $\mathrm{B},{ }^{7)}$ a triterpenoid with oleanane skeleton.

The FD-MS of 2 showed prominent peaks at $m / z 979$ $\left((\mathrm{M}+\mathrm{Na})^{+}\right), 833\left((\mathrm{M}+\mathrm{Na})-\mathrm{C}_{6} \mathrm{H}_{10} \mathrm{O}_{4}\right)^{+}$and $69((\mathrm{M}+$ $\left.\mathrm{Na})-\mathrm{C}_{12} \mathrm{H}_{20} \mathrm{O}_{9}\right)^{+}$and $691\left((\mathrm{M}+\mathrm{Na})-\mathrm{C}_{12} \mathrm{H}_{20} \mathrm{O}_{9}\right)^{+}$indicating the presence of glucuronyl-galactosyl-rhamnose moiety. Thus, the structure of 1 was strongly suggested to be soyasapoinin $I^{7)}$ and finally confirmed by direct comparison with authentic soyasaponin I kindly gifted by Dr. 


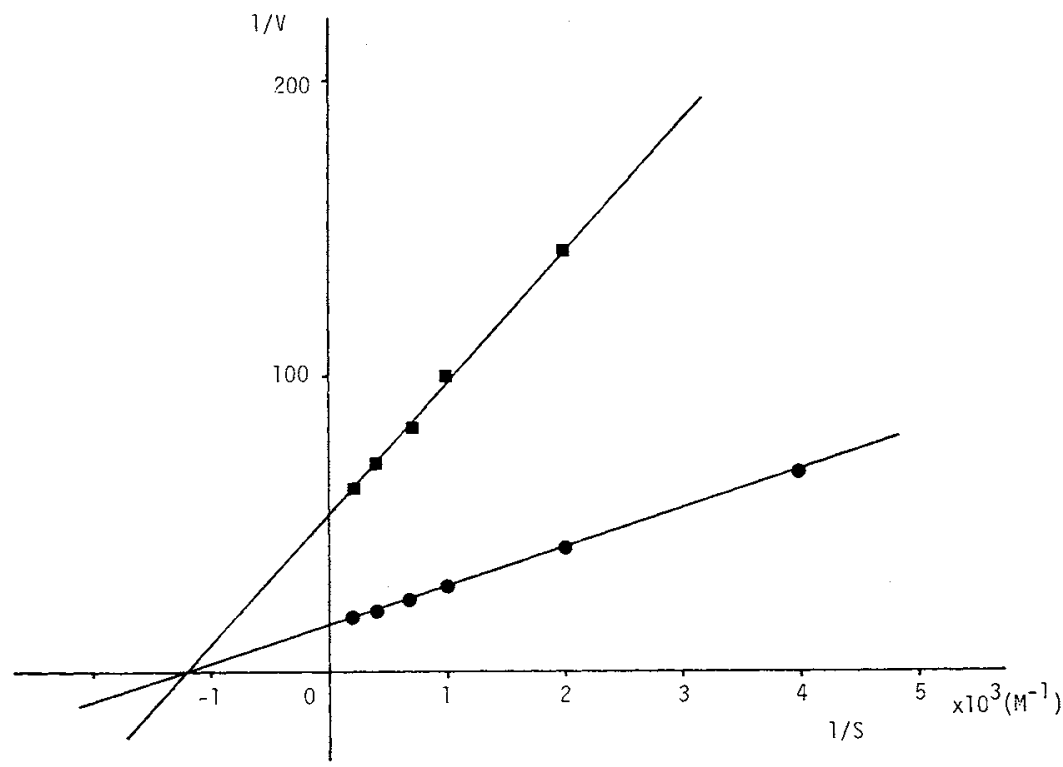

FrG. 1. Double Reciprocal Plots of the Inhibitory Effect of Soyasaponin I on Glycolate Oxidase.

a, soyasaponin I $500 \mathrm{ppm}$; O, control; S, substrate (glycolate).

\section{T. Yokota.}

As shown in Fig. 1, soyasaponin I (1) non-competitively inhibited glycolate oxidase $\left(\mathrm{ID}_{50}=5.0 \times 10^{-4} \mathrm{M}\right)$, whereas the sapogenin (3) and constituent sugars, glucuronic acid, rhamnose and galactose, were practically inactive. Further, it is of interest in connection with structureactivity relation that methyl ester (2) of soyasaponin I does not block the enzyme. Thus the inhibitory activity of $\mathbf{1}$ might be closely related to the whole structure of molecule. Although the plant physiological role of soyasaponin I has not been clarified, it is worthy to note that $\mathbf{1}$ inhibits the enzyme involved in the photorespiration and also that $\mathbf{1}$ has been recently isolated from seedlings of Alaska pea as a Pfr killer of the phytochrome system. ${ }^{8}$ )

The effects of 1 on the photorespiration is now under investigation.

Acknowledgments. We are grateful to Emeritus Professor S. Tamura for his guidance. We also thank to Dr. Y. Esumi of The Institute of Physical and Chemical Research for measurement of FD-MS spectra. This re- search was supported in part by a Grant-in-Aid for Scientific Research from the Ministry of Education, Science and Culture of Japan (No. 511604).

\section{REFERENCES}

1) I. Zelitch, Arch. Biochem. Biophys., 163, 367 (1974).

2) T. Kisaki and N. E. Tolbert, Plant Physiol., 11, 247 (1970).

3) I. Zelitch, Science, 196, 1450 (1977).

4) I. Zelitch, Plant Physiol., 41, 1623 (1966).

5) M. Nishida, S-B. Hyeon and A. Suzuki, Agric. Biol. Chem., 45, 2633 (1981).

6) I. Zelitch and S. Ochoa, J. Biol. Chem., 201, 707 (1953).

7) I. Kitagawa, M. Yoshikawa and I. Yoshioka, Chem. Pharm. Bull., 24, 121 (1976).

8) T. Yokota et al., Abstract of Papers, The Annual Meeting of Agricultural Chemical Society of Japan, Kyoto, 1981, p. 393. 